\title{
Scaling up cancer care in the WHO Eastern Mediterranean Region
}

Gemma Lyons ${ }^{1}$, Rengaswamy Sankaranarayanan ${ }^{2}$, Anthony B Miller ${ }^{3}$ and Slim Slama ${ }^{1}$

${ }^{1}$ WHO Regional Office for the Eastern Mediterranean, Cairo, Egypt (Correspondence to: Slim Slama: slamas@who.int) ${ }^{2}$ WHO International Agency for Research on Cancer, Lyon, France ${ }^{3}$ University of Toronto, Toronto, Canada.

Keywords: cancer; diabetes, cardiovascular diseases; noncommunicable diseases; policy

Citation: Lyons G, Sankaranarayanan R, Miller AB, Slama S. Scaling up cancer care in the WHO Eastern Mediterranean Region. East Mediterr Health J. 2018;24(1):104-110. https://doi.org/10.26719/2018.24.1.104

Received: 17/12/17; accepted: 08/02/18

Copyright (c) World Health Organization (WHO) 2018. Some rights reserved. This work is available under the CC BY-NC-SA 3.o IGO license (https:// creativecommons.org/licenses/by-nc-sa/3.o/igo).

\section{Introduction}

The burden of cancer in the Eastern Mediterranean Region (EMR) is predicted to double by 2030. Therefore, a strategic approach to scaling up cancer control in the Region is required. Currently, less than half of the countries in the Region have adopted a planned approach to cancer control, and access to cancer services is extremely variable. Early detection strategies often focus on screening rather than early diagnosis methods. Treatment access is varied, and half of the countries do not have guidelines in place for cancer treatment and referral. Other barriers to treatment include a lack of multi-disciplinary teams, limited access to cancer surgery, radiotherapy and medicines and a lack of specialist surgeons, oncologists and support staff. Similarly, palliative care access is challenging due to limited funding, inadequate training, insufficient staff and a lack of access to important pain relief medications. Global efforts to address noncommunicable diseases (NCDs), including cancer, are gaining momentum for countries at all levels of development, and cancer management and technologies are rapidly advancing. However, it is important that approaches are tailored to country settings, to ensure cost-effective use of modest budgets in low-resource settings.

The WHO EMR is made up of 22 countries in the Middle East and North Africa, with a total estimated population of 620 million (1). However, there is substantial variation in terms of population health outcomes, health care infrastructure and quality and level of health expenditure. This variability is largely related to economic development in a region that consists of low, middle and high-income countries (2). Furthermore, the backdrop of political instability, conflict and cultural practices presents a number of development challenges.

The Region, like much of the world, is experiencing an epidemiological transition from communicable diseases to NCDs such as cardiovascular diseases, diabetes and cancer (3). Many factors are contributing to this, including an ageing population and increasing levels of unhealthy lifestyle behaviours such as smoking, poor diet and inactivity. Indeed, more than $65 \%$ of deaths in the EMR are now directly attributed to NCDs (4).
Cancer is one of the four major killers in the Region and results in nearly 400000 deaths every year. Notably, the number of cases is projected to increase dramatically over the next 15 years, with the EMR expected to have the highest estimated increase in cancer burden of all six WHO regions. Furthermore, survival rates in the EMR are lower than in Europe and in the Americas, because patients usually present at a late stage when cancer is likely to be incurable (5).

However, many countries in the Region are working to reduce the burden of cancer and improve the availability of diagnostic tests, treatments and palliative care services. This commentary describes the cancer burden in the Region and the status of cancer control, including policies, early detection, treatment and palliative care. It outlines the need to scale up cancer control in the EMR, and also proposes a new regional framework for action on cancer control.

\section{Cancer burden in the Region}

Estimates from the International Agency for Research on Cancer (IARC) indicate around 293000 newly diagnosed cancer cases among women in the EMR in 2012 (5), and a total of 176000 women died of the disease. In the same year, the estimated numbers of cancer cases and deaths in men were 263000 and 191000 respectively. The five most common sites of cancer in men are lung, urinary bladder, liver, prostate and colorectal. Among women, breast cancer accounted for almost a third of all cancers followed by cervix and colorectal cancer. In 2012, breast cancer was the leading cause of cancer mortality 42000 deaths) in the Region, followed by lung cancer (29000 deaths) (5).

Furthermore, it has been projected that the burden of cancer will increase substantially in the period 20122030. Modelled figures suggest that cancer incidence and deaths will almost double, with 555000 new cases of cancer in 2012, compared to a prediction of 961000 new annual cancer cases by 2030. This is the highest projected increase of all six WHO regions (5). Population growth and increasing life expectancy are the main drivers behind most of the increase of cancer cases. However, lifestyle risk factors, including tobacco use, unhealthy 
diets, rising obesity, and insufficient physical activity levels contribute to these trends, offering entry points for preventive policies.

Notably, cancer survival rates in the EMR are lower than in the western regions, such as the Americas and Europe. Specifically, in the EMR there is a cancer death per 1.5 cancer cases, whereas in the Americas there is only one cancer death for every 2.2 people diagnosed (Table 1). Therefore, although the absolute number of cancer cases and deaths is much higher in the west, a person diagnosed with cancer in the EMR region is almost twice as likely to die, than a person diagnosed in the Americas.

Furthermore, there is substantial diversity of cancer profiles between EMR countries according to level of human development. For example, higher proportions of cervical cancers are found in countries with lower levels of development, such as Somalia or Djibouti while higher income countries record a higher proportion of colorectal cancers (6).

\section{Status of cancer control in the Region}

The status of cancer control in the Region varies by component, such as governance, early detection, treatment, palliative care and surveillance, and also by country. Broadly, all 22 countries in the Region are categorized into three groups based on level of development and income (2). Group 1 countries are the most developed, with increasing rates of NCDs, such as Bahrain and Qatar. The countries in group 2 are middle income, including Egypt and Morocco, whereas group 3 countries tend to be low-income, including Afghanistan, Sudan and Yemen. While all countries in the Region face challenges with regard to cancer care, these tend to vary with level of development, as well as conflicts and refugee situations.

\section{Policies and planning}

In 2005, a World Health Assembly resolution determined that all countries should implement a national cancer control programme (WHA58.22) (7). Further to this, given the resource limitations in all countries, it was proposed that they set up a National Cancer Control Committee to prioritize interventions, treatments and best use of resources, at the country level. Although some progress has been made in these areas, it has generally been slow in the Region.

Eight countries in the Region have an operational policy or strategy on cancer control, and three are partially implementing one; however, the remaining 10 member states $(45 \%)$ have not commenced implementation of a cancer strategy (Figure 1) (8). Furthermore, a multisectoral

\begin{tabular}{lccccccc}
\hline Table 1 Cancer incidence and mortality by WHO region, IARC Globocan, 2012 (5) & & & & Americas \\
$\begin{array}{l}\text { Cancer } \\
\text { epidemiology }\end{array}$ & $\begin{array}{c}\text { Africa } \\
\text { (AFRO) }\end{array}$ & $\begin{array}{c}\text { Amstern } \\
\text { (PAHO) }\end{array}$ & $\begin{array}{c}\text { Mediterranean } \\
\text { (EMRO) }\end{array}$ & $\begin{array}{c}\text { Europe } \\
\text { (EURO) }\end{array}$ & $\begin{array}{c}\text { Southeast Asia } \\
\text { (SEARO) }\end{array}$ & $\begin{array}{c}\text { Western Pacific } \\
\text { (WPRO) }\end{array}$ \\
\hline $\begin{array}{l}\text { Incidence } \\
\text { Mortality }\end{array}$ & 645071 & 2882425 & 555318 & 3714707 & 1724332 & 4543359 \\
$\begin{array}{l}\text { Ratio } \\
\text { (deaths : cases) }\end{array}$ & 455695 & 1294866 & 367441 & 1932760 & 1171282 & 2978084 \\
\hline
\end{tabular}

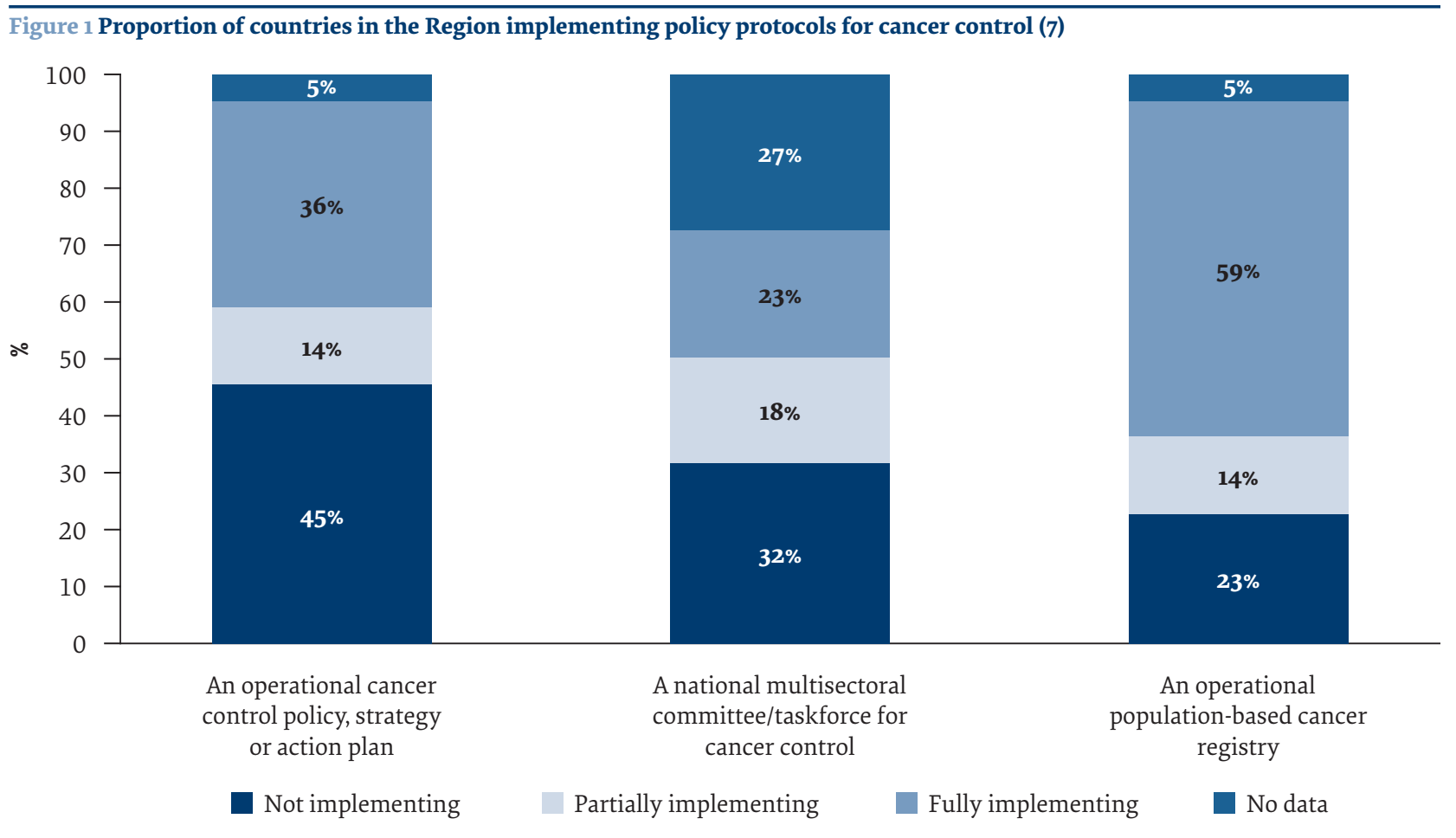


committee for cancer control is only available fully in five countries and partially in four. Although data is not available for all countries, at least seven Member States have not yet convened a committee. However, the majority of EMR countries $(73 \%)$ have a population-based cancer registry in place, covering a region (e.g., Karachi in Pakistan or Gharbiah registry in Egypt) or the whole country (e.g., Kuwait).

\section{Early detection of cancer}

One of the key areas of cancer control is early detection. This is the process of detecting the disease in its early stages when patients have higher survival rates. Early detection of cancer can be achieved through two methods: screening asymptomatic persons at a population-level, and early diagnosis of symptomatic patients (9). For early detection to be effective, integration with primary care is important, ensuring the rapid identification of symptoms, and prompt referral for diagnostic tests once cancer is clinically suspected. However, the integration of early detection into primary health care is limited in most countries in the Region, particularly low and middleincome countries (Table 2).

In January 2016, a consultative meeting was held to discuss the early detection and screening of priority cancers in the EMR (10). The two-day expert consultation was attended by a number of regional and international experts, and the recommendations included the development of policy briefs on five key cancers, which have since been published (11).

The five identified most common cancers amenable for early detection in the Region are breast, colorectal, cervical, prostate, and oral cancers. These five were identified based on their incidence and/or amenability to early detection. Breast cancer is the most common cancer among women and increasing in incidence in all countries of the Region, while colorectal and prostate cancers are also increasing in incidence. Furthermore, oral cancer is common in some countries due to the high prevalence of tobacco, toombak and qat chewing. Cancer of the uterine cervix is low in incidence in the Region; however, it is one of the most suitable cancers for screening interventions.

Breast cancer is amenable to early diagnosis, and prognosis can improve substantially if it is picked up early. There are some good examples of breast cancer early diagnosis initiatives in the Region. Jordan and Morocco provide good models for scaling up of breast cancer early detection in low- and middle-income countries worldwide. In Jordan, an education and awareness campaign has resulted in more early stage diagnoses and fewer breast cancer diagnoses at later stages, thus increasing survival rates. Between 2005 and 2009, the proportion of stage III diagnoses declined from $56 \%$ to $23 \%$ (12). Similarly, a nationwide awareness programme was implemented in Morocco, in addition to education for healthcare professionals, increasing early stage diagnoses of breast cancer (13).

While early diagnosis programmes have proven effective, evidence for population-level breast screening programmes is contentious, with a risk of over-diagnosis, and requiring substantial investment (14). Populationlevel mammography screening programmes have been initiated in many countries in the Region, however they generally have limited coverage and there has been little evidence to support their effectiveness to date (7). For example, a programme implemented in Bahrain in 2005 has had little impact on early diagnoses, which has been attributed to inconsistent performance and inadequate coverage $(15,16)$. Furthermore, in Qatar and Saudi Arabia, the ineffectiveness of breast screening services was attributed to low awareness of the general population and therefore inadequate participation $(17,18)$.

Even though some countries are implementing population-level screening programmes, the greatest impact on downstaging of cancer diagnoses in the Region has been galvanized through early diagnosis programmes, such as the examples on breast cancer in Jordan and Morocco. All countries can take steps to improve early diagnosis of cancer, this would require more focus on three critical elements: a) improving public awareness of different cancer symptoms and encourage people to seek care when these arise, and fighting stigma and cultural barriers; b) promoting health professional education on early signs and symptoms of common cancers, for prompt referral of symptomatic patients to diagnostic and treatment services; and c) investing in health services so that symptomatic patients receive timely diagnoses and access to safe and effective treatment without incurring prohibitive costs.

In summary, it is more cost-effective nationally, and better for patients individually, to diagnose cancer earlier and treat it effectively. This will result in increased survival rates, improved quality of life and lower cancer mortality. This reduces the burden of cancer on governments, as well as individuals and their families,

Table 2 Early detection of cancer integrated with primary health care (7)

\begin{tabular}{|c|c|c|c|c|c|}
\hline \multirow[t]{2}{*}{ Country group } & \multicolumn{5}{|c|}{$\begin{array}{l}\text { Primary health care service integration of early detection of cancers by means of rapid identification of the first } \\
\text { symptoms (availability, proportion of countries in the Region) }\end{array}$} \\
\hline & Breast & Cervix & Colon & Prostate & Oral \\
\hline Group 1 & $100 \%$ & $67 \%$ & $100 \%$ & $100 \%$ & $50 \%$ \\
\hline Group 2 & $70 \%$ & $40 \%$ & $10 \%$ & $0 \%$ & $0 \%$ \\
\hline Group 3 & $17 \%$ & $17 \%$ & $0 \%$ & $0 \%$ & $17 \%$ \\
\hline Total & $64 \%$ & $41 \%$ & $32 \%$ & $27 \%$ & $18 \%$ \\
\hline
\end{tabular}


while also contributing to international progress on NCDs.

\section{Cancer treatment}

Cancer treatment outcomes depend largely on two factors: stage at presentation and the availability of the required treatment services. Essential services include surgery, radiotherapy and systemic treatment with chemotherapeutic or hormonal agents. Approved national guidelines for cancer referrals and management are key elements of cancer control, ensuring a consistent and evidence-based best-practice approach to cancer care. However, this is an area of the cancer pathway in the EMR that needs more attention (Figure 2). Only around half of the countries in the Region have approved guidelines, most of which are high-income and upper middle-income countries. Comparatively, among lower income countries (group 3), only $17 \%$ have approved cancer management guidelines and none have protocols for onward referrals post-diagnosis.

Furthermore, service models incorporating multidisciplinary teams (MDTs) are important to ensure effective access to all treatment needs and continuity of care. MDTs involve specialties such as pathology, radiology, surgical, medical and radiation oncology. Certain counties in the Region, such as Jordan and Oman, have implemented MDTs in their model of cancer care. However, others including Pakistan and Sudan have not established multidisciplinary teams in their care pathway (19). There could be a number of reasons for this, including a lack of diagnostic facilities and/or treatment modalities.

Availability of cancer medicines is a challenge for several countries in the Region and access varies substantially by country (Table 3). Oncology medicines are free of charge for nationals in most EMR countries, however access varies based on the level of country development. For example, in Lebanon a significant portion of the Ministry of Health's budget is allocated on four extremely expensive oncology medicines; however, in Pakistan patients commonly have to pay even for those medicines included in the WHO essential list (19).

Another important element of cancer treatment is access to surgical interventions. While cancer surgery is available in most countries in the Region (77\%), the availability of specialist cancer surgery is limited in several countries (Table 3). The structure of surgical services for cancer patients varies from well-established surgical departments with specialized units for the treatment of different cancer sites such as breast, head and neck, digestive tract, to general surgical services

Figure 2 Availability of national guidelines for referral and management of cancer (7)

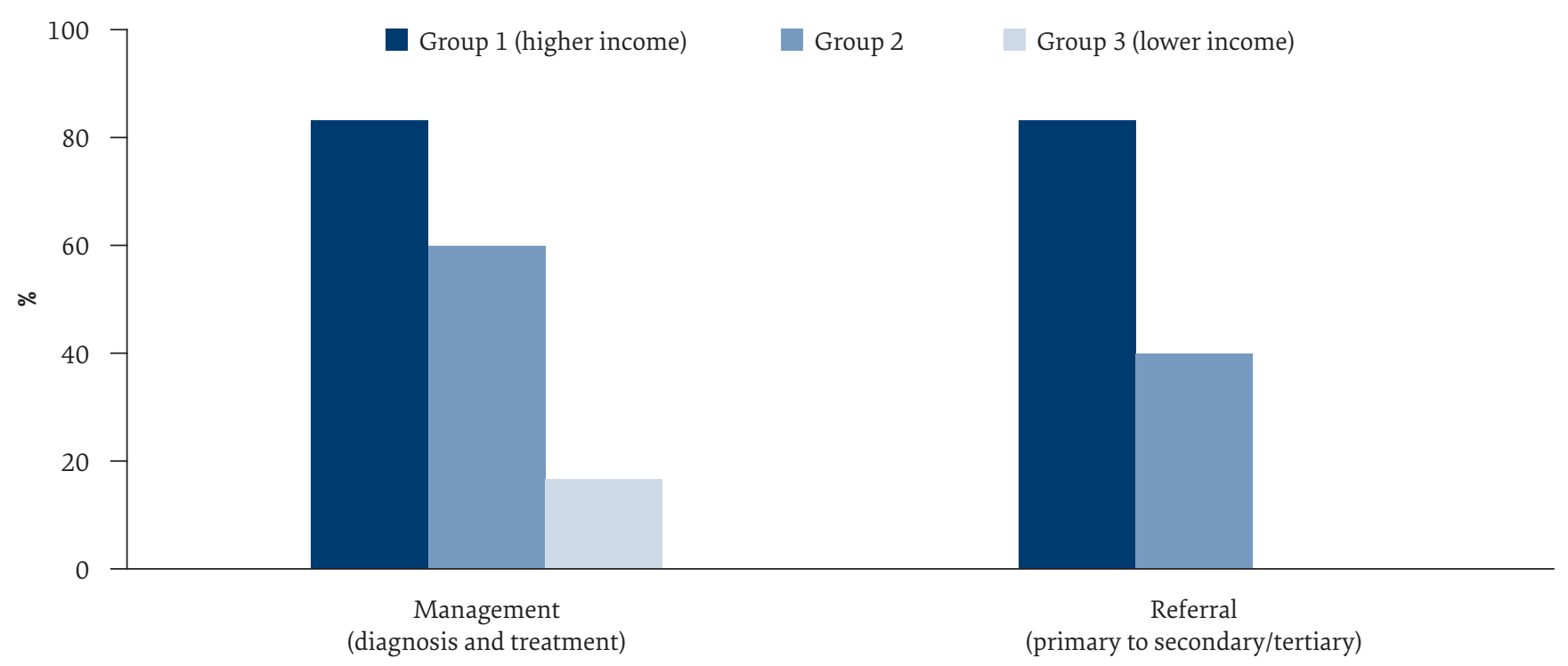

Table 3 Availability of cancer diagnosis and treatment services in the public sector (7)

\begin{tabular}{lcccc} 
Country group & $\begin{array}{c}\text { Availability of cancer diagnosis and treatment services in the public sector (\% of countries) } \\
\text { Cancer centres or cancer } \\
\text { departments at tertiary } \\
\text { level }\end{array}$ & $\begin{array}{c}\text { Pathology services } \\
\text { (laboratories) }\end{array}$ & Cancer surgery & Subsidized chemotherapy \\
\hline Group 1 & $100 \%$ & $100 \%$ & $83 \%$ & $100 \%$ \\
Group 2 & $80 \%$ & $90 \%$ & $90 \%$ & $80 \%$ \\
Group 3 & $50 \%$ & $50 \%$ & $50 \%$ & $50 \%$ \\
Total & $\mathbf{7 7 \%}$ & $\mathbf{8 2 \%}$ & $\mathbf{7 7 \%}$ & $\mathbf{7 7 \%}$ \\
\hline
\end{tabular}


Table 4 Availability of EMR palliative care funding and services (7)

\begin{tabular}{|c|c|c|c|}
\hline \multirow{2}{*}{ Country group } & \multicolumn{2}{|c|}{ Availability of palliative care in the public health system } & \multirow[t]{2}{*}{ Funding for palliative care } \\
\hline & In primary health care & In community or home-based care & \\
\hline Group 1 & $17 \%$ & $33 \%$ & $100 \%$ \\
\hline Group 2 & $10 \%$ & $10 \%$ & $60 \%$ \\
\hline Group 3 & $0 \%$ & $0 \%$ & $0 \%$ \\
\hline Total & $9 \%$ & $14 \%$ & $55 \%$ \\
\hline
\end{tabular}

without specialization in cancer where all surgeons can treat cancer patients (19).

Furthermore, modelled figures suggest that there is enough radiotherapy equipment to cover $60 \%$ of the Region's radiotherapy needs (20); however, equipment is not evenly distributed. While some countries have more available facilities than is needed, others have very limited facilities. Overall, it is evident that access to cancer treatment is variable both within and between countries. On top of this, the conflicts in the Region have further limited access to cancer treatments for many people. While it is clear that treatment availability must be improved across the Region, the current and future need for palliative care is also evident.

\section{Palliative care}

Despite the relatively low EMR cancer survival rates, palliative care needs are unaddressed in many countries, resulting in suffering of many terminally ill cancer patients during the final months of their life. The WHO Model of Palliative Care, developed in 1990, contains four domains: appropriate policies, adequate drug availability, education of health professionals and the public, and implementation of palliative care services (21); only three countries in the Region have palliative care available in the public health system (7). Furthermore, where present, palliative care services are at an early stage of development and not well integrated within the national health care system. Thus, many challenges exist within the areas of governance, human resources, training and medication availability for palliative care $(22,23)$.

The majority of the population in the Region has a limited understanding of palliative care services (22). Furthermore, most healthcare professionals have not undertaken any training on palliative care, since there is not a mandatory module in their education in most EMR countries (22). In addition, there is also a lack of specialist palliative care healthcare professionals and limited volunteers (22).

Notably, pain management availability and access to pain relief medications is restricted in many countries, resulting in low opioid consumption in the Region $(24,25)$. There are several reasons for this, including inadequate or overly strict legislation; unbalanced policies; limitations on available forms of medication especially oral opioids; lack of supply and distribution systems; limitations on who can prescribe; insufficient knowledge on the use of controlled medicines; and inappropriate attitudes towards controlled medicines $(22,23)$.
With limited funding for palliative care across much of the region, and no funding available in the lowest income countries (Table 4), the importance of nonstate actors, community organizations, and partnership working should not be understated.

\section{Conclusion}

As outlined, momentum and progress on cancer control has been increasing in the Region; however, a number of gaps and challenges remain. The cancer burden is rapidly increasing and this needs to be addressed strategically. Therefore, development of cancer policies, plans and guidelines is fundamental to this. Initiatives for prevention and early detection are needed to reduce the health and social burden on this complex region, and it is important that health professional training is scaled up to address this. Furthermore, treatment for cancer must be considered within health system contexts and economic feasibility, and it is vital that equity of access is addressed.

To improve treatment effectiveness, referral pathways must be developed and cancer-specific guidelines must be available to health professionals. Similarly, palliative care access must be scaled up holistically through awareness raising, health professional training, and improved access to pain relief medication. Although there has been progress in some elements of cancer control, a strategic and systematic approach to cancer has been lacking. However, in May 2017 the World Health Assembly discussed an agenda item titled "Cancer prevention and control in the context of an integrated approach". The Assembly representatives acknowledged the current global situation and urged Member States to take action, including scaling up national cancer control measures as part of national responses to NCDs (26).

In alignment with this increased global impetus, WHO/EMRO has developed a draft Framework for Cancer Control (Figure 3) (27). The document proposes a number of recommended strategic interventions in the six core areas of cancer control: governance; prevention; early detection; treatment; palliative care; and surveillance and research. The document has been developed through extensive consultation with global and regional experts, and was endorsed by the WHO Eastern Mediterranean Regional Committee in October 2017. The framework will support EMR countries to develop a more systematic approach to cancer control. 


\begin{tabular}{|c|c|c|}
\hline & Strategic interventions & Indicators \\
\hline $\begin{array}{l}\text { In the area of } \\
\text { governance }\end{array}$ & $\begin{array}{l}\text { - Develop a multi-sectoral strategy and action plan for cancer } \\
\text { prevention and control, as part of national NCD response } \\
\text { - Establish a national multi-sectoral committee for cancer } \\
\text { prevention and control } \\
\text { - Ensure sufficient national budget availability for cancer } \\
\text { - Define an essential cancer care package }{ }^{1} \text { and identify } \\
\text { financing mechanisms to reduce out-of-pocket expenditure } \\
\text { - Appoint a National Cancer Control Programme manager }\end{array}$ & $\begin{array}{l}\text { An operational, funded national multi-sectoral strategy/ } \\
\text { action plan encompassing all areas of cancer prevention and } \\
\text { control. }\end{array}$ \\
\hline $\begin{array}{l}\text { In the area of } \\
\text { prevention }\end{array}$ & $\begin{array}{l}\text { - Healthy lifestyle interventions in the areas of tobacco control, } \\
\text { physical activity, healthy diet and alcohol; in-line with the } \\
\text { Regional NCD Framework } \\
\text { - Ensure vaccination against hepatitis B in infancy } \\
\text { - Ensure Human Papillomavirus (HPV) vaccination in } \\
\text { preadolescents in countries with high risk of cervical cancer } \\
\text { - Eliminate or reduce exposure to occupational and } \\
\text { environmental carcinogens, such as asbestos }\end{array}$ & $\begin{array}{l}\text { - Five demand-reduction measures of the WHO FTFC }{ }^{2} \\
\text { - Four measures to reduce unhealthy diet }{ }^{3} \\
\text { - At least one national public awareness campaign on diet/ } \\
\text { physical activity, within the last } 5 \text { years } \\
\text { - Vaccination coverage against hepatitis B virus monitored } \\
\text { by the number of third doses of Hep-B vaccine (HepB3) } \\
\text { administered to infants }{ }^{4} \\
\text { - HPV vaccination coverage }\end{array}$ \\
\hline $\begin{array}{l}\text { In the area of } \\
\text { early } \\
\text { detection }\end{array}$ & $\begin{array}{l}\text { - Develop, implement and update evidence-based, nationally } \\
\text { approved guidelines/protocols/standards for the early } \\
\text { detection of priority cancers, with a focus on early diagnosis } \\
\text { - Promote community-awareness about the early symptoms of } \\
\text { priority cancers } \\
\text { - Promote health professional education on early signs and } \\
\text { symptoms of common cancers, for prompt referral of } \\
\text { symptomatic patients to diagnostic and treatment services } \\
\text { - Ensure availability, affordability and accessibility of } \\
\text { diagnostic tests for suspected cases } \\
\text { - Periodically assess effectiveness of early diagnosis and } \\
\text { screening programmes }\end{array}$ & $\begin{array}{l}\text { - Availability of evidence-based, nationally approved guidelines } \\
\text { for early detection of priority cancers } \\
\text { - Proportion of cancer patients diagnosed in early stages } \\
\text { - Reduction in cancer mortality rates for which early detection } \\
\text { programmes have been introduced } \\
\text { - Proportion of cancer patients who receive timely diagnosis } \\
\text { within one month of symptomatic presentation at primary } \\
\text { health care services } \\
\text { - Proportion of women between the ages of } 30-49 \text { screened } \\
\text { for cervical cancer at least once, or more often, and for lower } \\
\text { or higher age groups according to national programmes or } \\
\text { policies }\end{array}$ \\
\hline $\begin{array}{l}\text { In the area of } \\
\text { management }\end{array}$ & $\begin{array}{l}\text { - Develop, implement and update evidence-based, nationally } \\
\text { approved guidelines/protocols/standards for management of } \\
\text { priority cancers } \\
\text { - Assess the human resource requirements and develop plans } \\
\text { to scale up to meet local needs } \\
\text { - Ensure availability, affordability and accessibility of an } \\
\text { essential cancer care package }{ }^{1} \\
\text { - Strengthen coordination of referral system with targets to } \\
\text { reduce delays to diagnosis and treatment }\end{array}$ & $\begin{array}{l}\text { - Availability of evidence-based guidelines/protocols/standards } \\
\text { for management of priority cancers } \\
\text { - Proportion of patients who complete a course of prescribed } \\
\text { treatment } \\
\text { - Availability of national human resources strategies and plans }\end{array}$ \\
\hline $\begin{array}{l}\text { In the area of } \\
\text { palliative } \\
\text { care }\end{array}$ & $\begin{array}{l}\text { - Ensure inclusion of palliative care within national cancer } \\
\text { control plans } \\
\text { - Develop, implement and update evidence-based, nationally } \\
\text { approved guidelines/protocols/standards for palliative care } \\
\text { - Introduce palliative care into the curricula of healthcare } \\
\text { professionals } \\
\text { - Develop affordable, multidisciplinary integrated palliative } \\
\text { care services, including pain relief, psychosocial and spiritual } \\
\text { support, in both hospital and community settings } \\
\text { - Ensure availability and accessibility of opioids, analgesics and } \\
\text { other essential palliative care medicines, addressing legal and } \\
\text { regulatory barriers }\end{array}$ & $\begin{array}{l}\text { - Availability of national guidelines/protocols/standards for } \\
\text { palliative care } \\
\text { - Access to palliative care assessed by morphine-equivalent } \\
\text { consumption of strong opioid analgesics (excluding } \\
\text { methadone) per death from cancer }{ }^{4} \\
\text { - Availability of training programmes for healthcare } \\
\text { professionals }\end{array}$ \\
\hline $\begin{array}{l}\text { In the area of } \\
\text { surveillance } \\
\text { and research }\end{array}$ & $\begin{array}{l}\text { - Establish and strengthen hospital- and population-based } \\
\text { cancer registries that cover a population not less than one } \\
\text { million } \\
\text { - Develop a system to monitor quality of care and the } \\
\text { performance of national cancer control programmes } \\
\text { - Develop and implement a cancer research plan relevant to } \\
\text { country needs }\end{array}$ & $\begin{array}{l}\text { - Cancer incidence, by type of cancer, per } 100 \text { ooo population }{ }^{4} \\
\text { - Availability of progress / gap analysis on implementation of } \\
\text { national cancer control plan } \\
\text { - Number of peer reviewed publications related to cancer }\end{array}$ \\
\hline
\end{tabular}

1 Cancer care package includes diagnostic procedures, medicines and technologies, surgery and radiotherapy, and survivorship care

2 Tobacco demand reduction measures, WHO NCD Progress monitor 2017: Increased excise taxes and prices; smoke-free policies; large graphic health warnings/plain packaging; bans on advertising, promotion and sponsorship; mass media campaigns

3 Unhealthy diet reduction measures, WHO NCD Progress monitor 2017: salt/sodium policies; saturated fatty acids and trans-fats policies; marketing to children restrictions; marketing of breast-milk substitutes restrictions

4 These are from the WHO 25 indicators of the Global Monitoring Framework on NCDs (http://www.who.int/nmh/ncd-tools/indicators-definition/en/)

Priority cancers for early detection can be selected based how amenable they are to early detection, and on their incidence (and projected future incidence) within the country 


\section{Funding: None.}

\section{Competing interests: None declared.}

\section{References}

1. World Health Organization. Data repository. Geneva: World Health Organization; 2016 (http://who.int/gho/database/en).

2. World Health Organization Regional Office for the Eastern Mediterranean (EMRO). Technical Paper EM/RC59/Tech.Disc.1: Health systems strengthening in countries of the Eastern Mediterranean Region: challenges, priorities and options for future action. Cairo: EMRO; 2012 (http:// apps.who.int/iris/bitstream/1/123147/10665/RC_Resolutions_14693_3_2012_EN.pdf, accessed 11 May 2017).

3. Wahdan MH. The epidemiological transition. East Mediterr Health J. 20-2:8;1996. (http://applications.emro.who.int/emhj/o201/ emhj_20_8_1_2_1996.pdf).

4. World Health Organization Regional Office for the Eastern Mediterranean (EMRO). Noncommunicable diseases. Cairo: EMRO; 2017 (http:// www.emro.who.int/entity/ncds/index.html).

5. International Agency for Research on Cancer (IARC) and Word Health Organization. GLOBOCAN 2012: estimated cancer incidence, mortality and prevalence worldwide in 2012. Geneva: World Health Organization; 2012 (http://globocan.iarc.fr/Pages/fact_sheets_population.aspx).

6. Kulhánová I, Bray F, Fadhil I, Al-Zahrani AS, El-Basmy A, Anwar WA, et al. Profile of cancer in the Eastern Mediterranean Region: the need for action. Cancer Epidemiol. 32-47:125;04 2017. https://doi.org/10.1016/j.canep.2017.01.009 PMID:28268206.

7. World Health Organization. World Health Assembly Resolution WHA58.22: Cancer prevention and control. Geneva: World Health Organization; 2005. (http://www.who.int/cancer/media/news/WHA-2022\%58en.pdf).

8. World Health Organization Regional Office for the Eastern Mediterranean (EMRO). Assessing national capacity for the prevention and control of noncommunicable diseases: report of the 2015 country capacity survey in the Eastern Mediterranean Region. Cairo: EMRO; 2016 (http:// applications.emro.who.int/dsaf/EMROPUB_2016_EN_19168.pdf?ua=1\&ua=1).

9. World Health Organization. Guide to cancer early diagnosis. Geneva: World Health Organization; 2017 (http://apps.who.int/iris/bitstre am/-9789241511940/1/254500/10665eng.pdf?ua=1).

10. World Health Organization Regional Office for the Eastern Mediterranean (EMRO). Summary report on the consultative meeting on early detection and screening of priority cancers in the Eastern Mediterranean Region. Cairo: EMRO; 2016 (http://applications.emro.who.int/docs/ IC_Meet_Rep_2016_EN_16607.pdf?ua=1).

11. World Health Organization Regional Office for the Eastern Mediterranean (EMRO). Policy statements and recommended actions for early detection of cancer in the Eastern Mediterranean Region. Cairo: EMRO; 2016 (http://www.emro.who.int/noncommunicable-diseases/ publications/policy-statements-ncds.html).

12. Taha H. (2015). A bottom-up model for strengthening breast cancer early detection services in Jordan. Amman: King Hussein Cancer Foundation; 2015 (http://g2hp.net/wp-content/blogs.dir/2/files/downloads/o8/2012/Taha-2012-Strengthening-Breast-Cancer.pdf).

13. Obtel M, Lyoussi B, Tachfouti N, Pelissier SM, Nejjari C. Using surveillance data to understand cancer trends: an overview in Morocco. Arch Public Health. 45:(1)73;2 11 2015. https://doi.org/10.1186/s8-0094-015-1369o PMID:26528393

14. Lauby-Secretan B, Scoccianti C, Loomis D, Benbrahim-Tallaa L, Bouvard V, Bianchini F, et al.; International Agency for Research on Cancer Handbook Working Group. Breast-cancer screening-viewpoint of the IARC Working Group. N Engl J Med. 2015 Jun 8-2353:(24)372;11. https://doi. org/10.1056/NEJMsr1504363 PMID:26039523

15. Al Hajeri A. Prospective view of breast cancer in Bahrain. J Bahrain Med Soc. 104:(3)24;2013.

16. Hamadeh RR, Abulfatih NM, Fekri MA, Al-Mehza HE. Epidemiology of breast cancer among Bahraini women: data from the Bahrain Cancer Registry. Sultan Qaboos Univ Med J. 2014 May;2)14):e82-176. PMID:24790739

17. Donnelly TT, Khater AH, Al-Bader SB, Al Kuwari MG, Malik M, Al-Meer N, et al. Factors that influence awareness of breast cancer screening among Arab women in Qatar: results from a cross sectional survey. Asian Pac J Cancer Prev. 64-10157:(23)15;2014. https://doi.org/10.7314/ APJCP.2014.15.23.10157 PMID:25556441

18. El Bcheraoui C, Basulaiman M, Wilson S, Daoud F, Tuffaha M, AlMazroa MA, et al. Breast cancer screening in Saudi Arabia: free but almost no takers. PLoS One. 3)10;16 03 2015):e0119051. https://doi.org/10.1371/journal.pone.0119051 PMID:25774520

19. World Health Organization Regional Office for the Eastern Mediterranean (EMRO). Access to essential technologies for cancer diagnosis and treatment in the Eastern Mediterranean Region. Cairo: EMRO; 2016. Unpublished survey.

20. IAEA. Directory of radiotherapy centres. Vienna: IAEA; 2016 (https://dirac.iaea.org)

21. Stjernswärd J, Foley KM, Ferris FD. The public health strategy for palliative care. J Pain Symptom Manage. 2007 May;93-486:(5)33. https://doi. org/10.1016/j.jpainsymman.2007.02.016 PMID:17482035

22. Fadhil I, Lyons G, Payne S. Barriers to, and opportunities for, palliative care development in the Eastern Mediterranean Region. Lancet Oncol. 2017 Mar;3)18):e84-176. https://doi.org/10.1016/S8-30101(17)2045-1470 PMID:28271872

23. Silbermann M, Arnaout M, Daher M, Nestoros S, Pitsillides B, Charalambous H, et al. Palliative cancer care in Middle Eastern countries: accomplishments and challenges. Ann Oncol. 2012 Apr;23 Suppl 28-3:15. https://doi.org/10.1093/annonc/mdso84 PMID:22628412

24. Pain and Policy Studies Group and University of Wisconsin-Madison. Opioid consumption data (http://www.painpolicy.wisc.edu/opioidconsumption-data).

25. World Health Organization Regional Office for the Eastern Mediterranean (EMRO). Briefing note on access to controlled medicines: balanced policy approach between responsible use and misuse. Cairo: EMRO; 2016.

26. Seventieth World Health Assembly. Cancer prevention and control in the context of an integrated approach (Agenda item 15.6). Geneva: world Health Organization; 31 May 2017 (http://apps.who.int/gb/ebwha/pdf_files/WHA70/A70_R-12en.pdf).

27. World Health Organization Regional Office for the Eastern Mediterranean (EMRO). Regional Committee Resolution EM/RC64/R.2: Regional framework of action on cancer control and prevention. Cairo: EMRO; 2017 (http://applications.emro.who.int/docs/RC64_Resolutions_2017_ R2_20127_EN.pdf?ua=1). 